\title{
Applying probabilistic method base on Monte Carlo simulation to analyze slope stability on route Nha Trang - Da Lat (within Khanh Vinh district, Khanh Hoa province)
}

- Nguyen Thanh Danh

- Dau Van Ngo

- Ta Quoc Dung

University of Technology, VNU-HCM

(Manuscript Received on August 19 th $^{\text {th }}$ 2014; Manuscript Revised November 11 $1^{\text {th }}$, 2014)

ABSTRACT:

In this paper, a Monte Carlo simulation used to analyze probabilistic slope stability. The results including: probabilistic slope failure and reliability index with respect to factor of safety under the effects of uncertainties in the parameters of soil properties. Base on this informations, geotechnical engineers how to get optimal designs to prevent slope failure. In addition, the purpose of

Keywords: Monte Carlo simulation, slope stability, factor of safety, reliability index.

\section{INTRODUCTION}

To promote economic-social development between Khanh Hoa and Lam Dong provinces, cooperate to develop tourism between the Nha Trang and Da Lat cities, the goverment of two these provinces agreed to open new route from Nha Trang to Da Lat $131.5 \mathrm{~km}$ in length (shorter route Nha Trang - Phan Rang - Dalat about $90 \mathrm{~km}$ ) on march $29^{\text {th }}, 2002$. The route was started to construct on April 20 th, 2014 and put to service on April $27^{\text {th }}, 2007$. The route includes two DT723 and DT652 provincial roads connecting together, DT723 provincial highway is from Highway 20 through the Lac Duong district and Da Lat city (Lam Dong), DT652 provincial highway passes through Khanh Vinh Dien Khanh the districts (Khanh Hoa) and connect to the national Highway $1 \mathrm{~A}$.

Due to high terrain, steep slopes and complexly geological structures the severe landslides are regular occurring along this route, destroy roads, cause traffic this paper is to show that standard deviation of soil properties can be applied in simple ways, without more data, time, or effort than are commonly available in geotechnical engineering practice. Applying Monte Carlo simulation to evaluate probabilistic slope stability on route Nha Trang Da Lat.

jams and threaten to the safety of persons and vehicles when in traffic, especially during the rainy season every year. Currently, under climate change, landslide hazard occur on this route increasing both the frequence and scale.

The studying of prevention and mitigation of damage caused by the landslide hazard on this route has been interested by local government in recent years. The Department of Science and Technology of Khanh Hoa in collaboration with the Division For Water Resources Planning And Investigation For The Central Region of Vietnam to implement the project "Studying geological conditions, hydrology in moutainous Khanh Son and Khanh Vinh districts. Proposing solutions to construct works of sustainable transportation and irrigation" from 2009 to 2011 . The project was initially given the basic causes and solutions to prevent landslides on the route of Nha Trang - Da Lat.

\section{Trang 76}


According to the classical approach (limiting equilibrium methods), the slope stability analysis is based on the determining factors of safety corresponding to the physical-mechanical parameters of soil at a specific time and space. As a result, the slope is considered safe only if the calculated the factor of safety clearly exceeds unity, whereas, it is unstable. Do not consider temporal and spatial variability of soil properties, such as bulk density, angle of internal friction, cohesion and pore water pressure as well as geological details missing in the exploration program, testing errors, model uncertainty reflecting the inability of the simulation model, design technique or empirical formula to represent the true physical behavior of the system, such as the calculation of the safety factor of slopes using limit equilibrium methods and many other relevant factors, therefore affecting the accuracy of the safety of factor [1]. The safety of factor determined by the classical method is relative, not quantify the degree of slope stability and not be economical.

To overcome these limitations, using the Monte Carlo simulation to analyze the probability of slope stability is a reasonable choice, the calculated results conform to reality and optimize in the design of the retaining works $[1,2]$.

\section{MOTE CARLO METHOD}

The probabilistic approach applied to slope stability analysis allows to consider the impact of the variation of the input parameters as well as its affects to the probability of failure of the slope. Monte Carlo simulation consists of the following steps $[1,3,4]$ :

Determine the slope geometry and determine the probability distribution function for physicalmechanical parameters of soil.

Search for the critical slip surface and factor of safety using limit equilibrium methods, such as modeling Ordinary, Bishop, Janpu, Spencer, Morgenstern-Price or finite element stress method based on average values of the input parameters. Once the critical slip surface and the uncertainties of soil properties are known (or assumed), the probability and reliability analysis can be performed.
Determine randomly the next set new values for the parameters basis on theirs the assigned probability distribution and determine multiple times safety of factor.

Then the factor of safety for each set can be calculated using any limiting equilibrium method or finite element stress method. Accordingly, the mean, the standard deviation and the associated probability distribution of the factor of safety are determined. Finally, the reliability index and the probability of failure with respect to the factor of safety lower than one can be calculated.

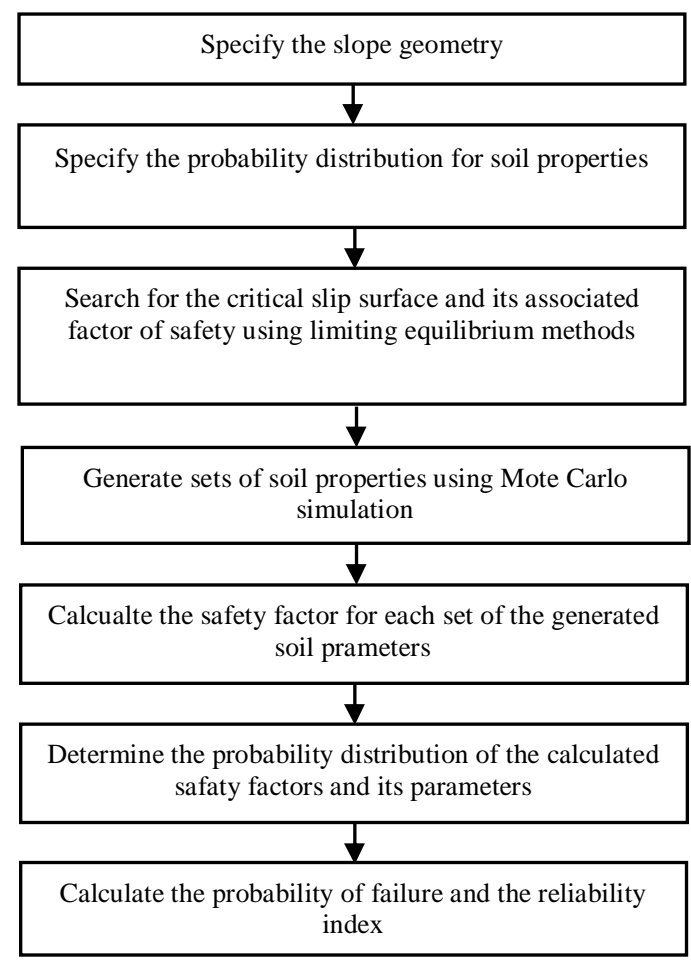

Fig. 1. Schematic representation of methodology used

\subsection{Uncertain soil parameters}

Many researchs are assumed a normal distribution for the parameters of soil properties (Lumb, 1966; Matsuo and Kuroda, 1974; Tobutt, 1982; Tan, Donald and Melchers,1993). Choice of parameters does based on level degrees of the variability of parameters and level degrees theirs affects to safety factor. According to Christian (1994) and Lumb (1996), significant parameters uncertainties of soil properties in slope stability analysis including unit weight $(\gamma)$, angle of internal friction $(\varphi)$ and cohesion $(c)$. Therefore, in this 
study the parameter $\gamma, \varphi$ and $\mathrm{c}$ were selected for analysis. Each parameter is required statistics to determine the mean value $(\mu)$, standard deviation $(\sigma)$ as well as correlation coefficient $(r)$ between $\varphi$ and $c$. Most current statistical software utilities are available for calculating the statistics.

\subsection{Standard deviation}

If the number of statistical samples are large enough, the standard deviation $(\sigma)$ is determined by the formula (1). Whereas, the standard deviation can be determined by the formula (2) or (3) [5]. $\sigma=\sqrt{\frac{\left(x_{i}-\bar{x}\right)^{2}}{n-1}}$

$\sigma=\operatorname{cov}(x) \mu$

$\sigma=\frac{x_{\max }-x_{\min }}{6}$

Where: $x_{i}$ is the $i$ th value of the parameter $x ; \bar{x}$ is the average value of the parameter $x ; n$ is the sum of statistical samples; $\operatorname{cov}(x)$ is the coefficient of variation on experience (Table 1); $x_{\max }, x_{\min }$ are the largest and smallest values of the parameter $x$.

Table 1. Values cov on experience of the various authors

\begin{tabular}{|l|c|c|c|}
\hline \multirow{2}{*}{ Authors } & \multicolumn{3}{c|}{ cov } \\
\cline { 2 - 4 } $\begin{array}{l}\text { Harr (1984), Kulhawy } \\
\text { (1992) }\end{array}$ & & $0,02-0,13$ & $0,03-0,07$ \\
\hline Schultze (1971) & & 0,053 & \\
\hline Phoon (1995) & & $0,05-0,11$ & \\
Sand & & $0,15-0,5$ & \\
Clay & & $0,04-0,23$ & \\
Mud & & & \\
\hline Lumn (1996) & $0,16-0,32$ & & \\
\hline NEN (1997) & 0,2 & 0,1 & \\
\hline Geodelf (1998) & 0,2 & 0,1 & \\
\hline JCSS (2002) & $0,1-0,5$ & & \\
\hline Baecher và Christian (2003) & & & \\
Sand & & $0,05-0,15$ & \\
Clay & $0,2-0,5$ & $0,12-0,56$ & \\
\hline Babu (2004) & $0,125-0,4$ & & \\
\hline Bakker (2004) & 0,275 & & \\
\hline
\end{tabular}

\subsection{Correlation coefficient}

The correlation coefficient $(r)$ represents close relationship between $\varphi$ and $c$ defined by the formula (4). The correlation coefficient is always ranges from -1 to 1. However, laboratory tests on range of soil types showed that the shear strength parameters $\varphi$ and $c$ are often negatively correlated with correlation coefficient ranges from -0.72 to 0.35 (Lumb, 1970; Grivas, 1981 and Wolff, 1985). When the positive correlation coefficient, $\varphi$ and $c$ are positively correlated implying that lager values of $c$ are more likely to occur with lager values of $\varphi$. Similarly, when the negative correlation coefficient, $\varphi$ and $c$ are negatively correlated and reflects tendency of a lager value of $c$ to occur with a smaller value of $\varphi$. A zero correlation coefficient implies that $\varphi$ and $c$ are independent parameters (or uncorrelated). Correlation between strength parameters may affect the probability failure of a slope. Furthermore, the assumption of independent (uncorrelated) soil properties ( $\varphi, c$ and $\gamma$ ) is reported by various researchers (Matsuo and Kuroda, 1974; Matsuo, 1976; Yucemen et. al, 1985; Dettinger and Wilson, 1981; Chowdhury and Xu, 1993; Christian and et. al, 1994), or correlation between strength parameters is negligible (Lamb, 1970, 1974).

$$
r=\frac{\sum\left(x_{i}-\bar{x}\right)\left(y_{i}-\bar{y}\right)}{\sqrt{\sum\left(x_{i}-\bar{x}\right)^{2} \sum\left(y_{i}-\bar{y}\right)^{2}}}
$$

\section{Trang 78}


Where: $x_{i}, y_{i}$ are the $i$ th values of the parameters $x$ and $y ; \bar{x}, \bar{y}$ are the average values of the parameters $x$ and $y$.

\subsection{Reliability index}

Reliability analysis is used to assess uncertainties in engineering variables such as the factor of safety of slope stability. The reliability index $(\beta)(5)$ is often used to express the degree of uncertainty in the calculated mean factor of safety $\left(F S_{\text {mean }}\right)$.

$\beta=\frac{F S_{\text {mean }}-1}{\sigma}$

Reliability index depends on the standard deviation and directly proportional with the probability failure. The smaller the probability failure is the higher reliability index is and vice versa. Reliability index can also be expressed by the following formula [6]:

$\beta=\frac{F S_{\text {mean }}-1}{F S_{\text {mean }} \operatorname{cov}(F S)}$

From (6), it is easy to select design values of FSmean that have the same reliability index. For example, to
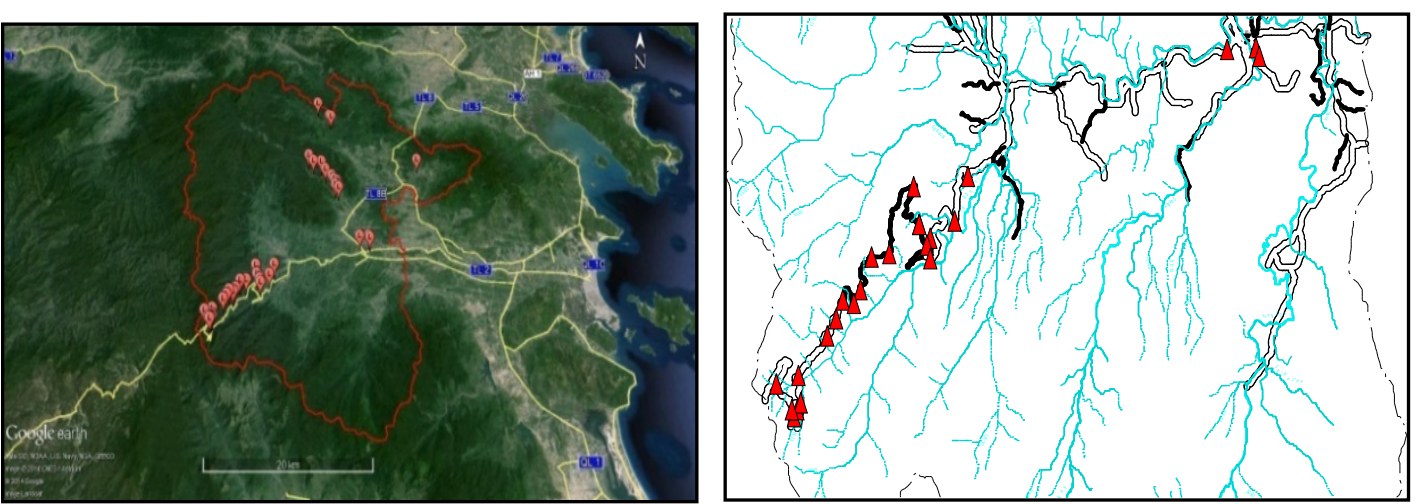

Fig. 2. The landslide locations on routes Nha Trang - Da Lat

Table 2. Location, soil type and geometry of slope analysis

\begin{tabular}{|c|c|c|c|l|c|c|}
\hline \multirow{2}{*}{$\mathbf{N}_{\mathbf{0}}$} & \multirow{2}{*}{ Slope } & \multicolumn{2}{|c|}{ Coordinate (VN2000) } & Soil type & High slope (m) & $\begin{array}{c}\text { Slope angle } \\
\text { (Degree) }\end{array}$ \\
\cline { 3 - 5 } & & $\mathrm{X}$ & $\mathrm{Y}$ & & 18 & 60 \\
\hline 1 & VS26 & 551881 & 1347492 & Sandy clay mixed with gravel & 20 & 60 \\
\hline 2 & VS69 & 563209 & 1356763 & Clayey sand mixed with gravel & 6 & 43 \\
\hline 3 & VS352 & 567001 & 1365256 & Clayey sand mixed with gravel & 6 & 60 \\
\hline 4 & VS87 & 569414 & 1355284 & Sandy clay mixed with gravel & & 6 \\
\hline
\end{tabular}

\section{RESULTS}

Case 1: $\sigma$ and $r$ values are determined according to the survey data [7], the analysis for all four slopes

achieve $\beta$ of 2 , when $\operatorname{cov}(F S)$ is 0.2 , the computed FSmean must be 1.67 , but, when $\operatorname{cov}(F S)$ is 0.1 , the computed FS $\mathrm{S}_{\text {mean }}$ need be only 1.25 . Thus, the reliability index expressed in terms of the coefficient of variation of the factor of safety provides an internally consistent criterion for design.

\section{APPLICATION}

Using the Monte Carlo method was integrated in Slope/W of the software Geostudio 2004 to analyze probability failure of four slopes VS26, VS69, VS87 and VS352 along the route, each slope is made up of one of three soil types following: sandy clay, sandy clay mixed with gravel and clayey sand mixed with gravel which is original from eluvi, deluvi and proluvi overlay the slightly weathered granite or the slightly weathered rhyolite. At position of slopes, the groundwater table is very deep or no groundwater [7]. The soil properties in the calculation include uncertain parameters as $\varphi, c$ and $\gamma$. 
Table 3. The statistical parameters of soil obtain from survey results

\begin{tabular}{|l|c|c|c|c|c|c|c|}
\hline \multirow{2}{*}{ Soil type } & \multicolumn{2}{|c|}{$\gamma\left(\mathbf{k N} / \mathbf{m}^{\mathbf{3}}\right)$} & \multicolumn{2}{c|}{$\varphi$ (Degree) } & \multicolumn{2}{c|}{$c(\mathbf{k P a})$} & \multirow{2}{*}{$r$} \\
\cline { 2 - 7 } & $\mu$ & $\sigma$ & $\mu$ & $\sigma$ & $\mu$ & $\sigma$ & -0.03 \\
\hline Sandy clay (epdQ) & 17.38 & 1.1 & 15.92 & 1.0 & 20.77 & 4.1 & 0.13 \\
\hline $\begin{array}{l}\text { Sandy clay mixed with } \\
\text { gravel (epdQ) }\end{array}$ & 17.98 & 1.2 & 18.25 & 1.0 & 17.25 & 2.7 & 0.12 \\
\hline $\begin{array}{l}\text { Clayey sand mixed with } \\
\text { gravel (epdQ) }\end{array}$ & 17.29 & 1.4 & 17.38 & 2.9 & 15.25 & 2.9 & \multirow{2}{*}{} \\
\hline
\end{tabular}

Table 4. Results of case 1 (Fig. 3-14)

\begin{tabular}{|l|c|c|c|c|}
\hline \multirow{2}{*}{ Statistical parameters } & \multicolumn{4}{c|}{ Slope } \\
\cline { 2 - 5 } & VS26 & VS69 & VS87 & VS352 \\
\hline The mean factor of safety, $F S_{\text {mean }}$ & 0.67 & 0.59 & 1.12 & 2.42 \\
\hline Reliability index, $\beta$ & -6.40 & -5.20 & 0.97 & 1.84 \\
\hline Probability failure, $P(\%)$ & 100 & 100 & 16.4 & 0.21 \\
\hline Standard deviation, $\sigma$ & 0.05 & 0.08 & 0.12 & 0.44 \\
\hline The minimum factor of safety, $\mathrm{FS}_{\min }$ & 0.42 & 0.24 & 0.56 & 2.25 \\
\hline The maximum factor of safety, $\mathrm{FS}_{\max }$ & 0.87 & 9.40 & 1.64 & 1500 \\
\hline Number of Mote Carlo trials & 1500 & 1500 & 1500 & \\
\hline
\end{tabular}

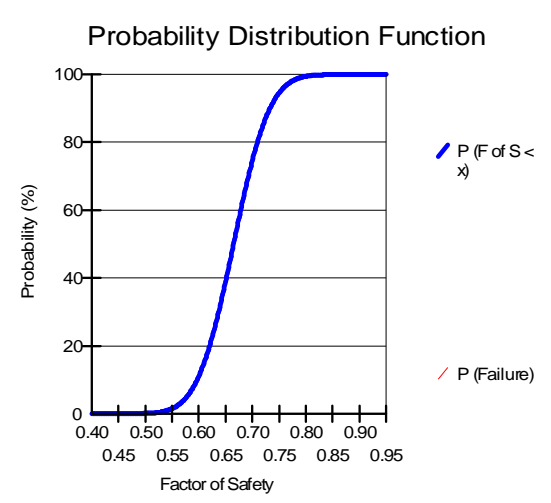

Fig. 3. The probability distribution curve (VS26)

Probability Distribution Function

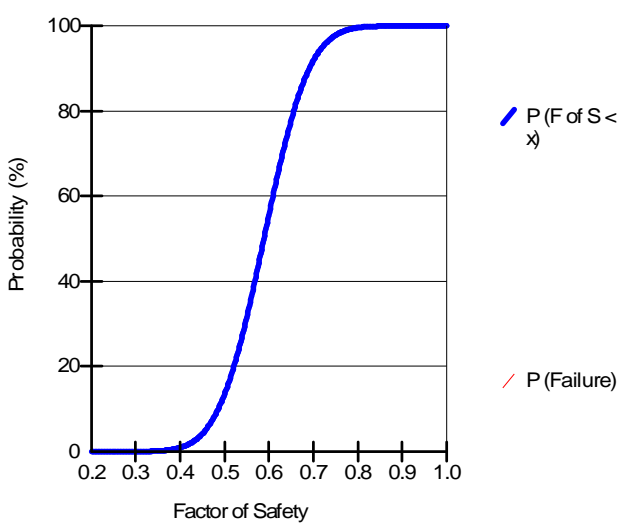

Fig. 5. The probability distribution curve (VS69)

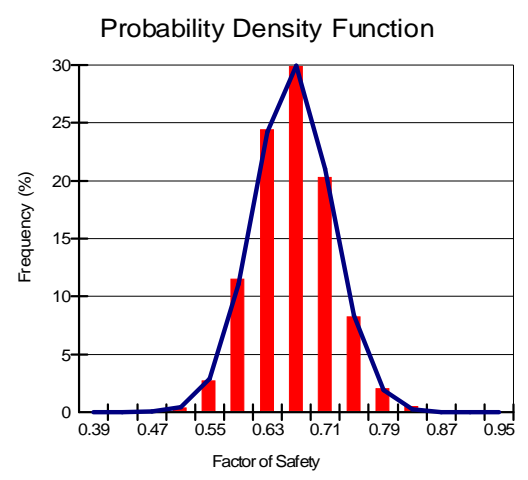

Fig. 4. The normal distribution curve (VS26)

Probability Density Function

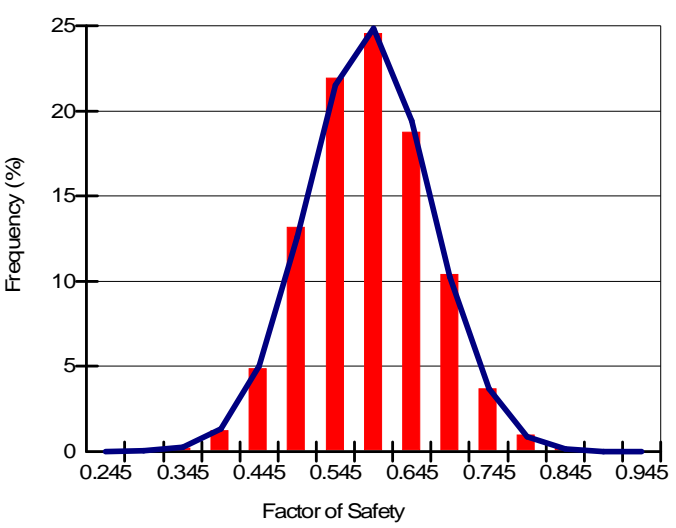

Fig. 6. The normal distribution curve (VS69)

\section{Trang 80}


Probability Distribution Function

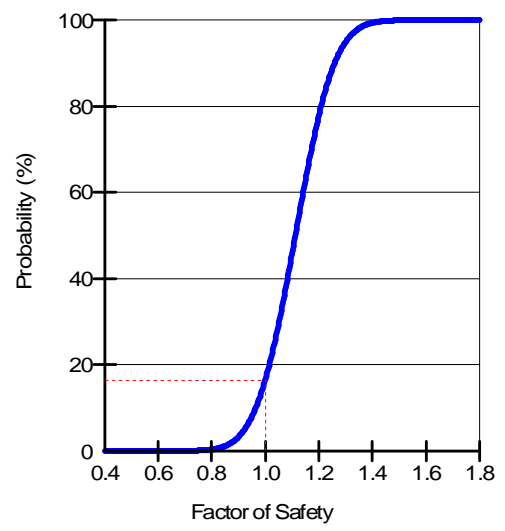

Fig. 7. The probability distribution curve (VS87)

\section{Probability Distribution Function}

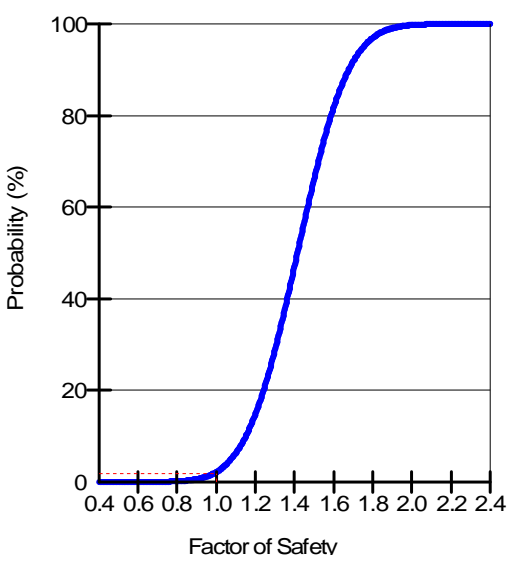

Fig. 9. The probability distribution curve (VS352)

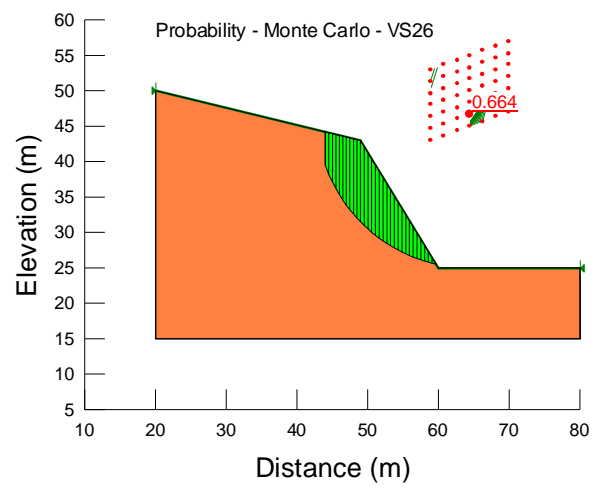

Fig. 11. Slip surface (VS26)
Probability Density Function

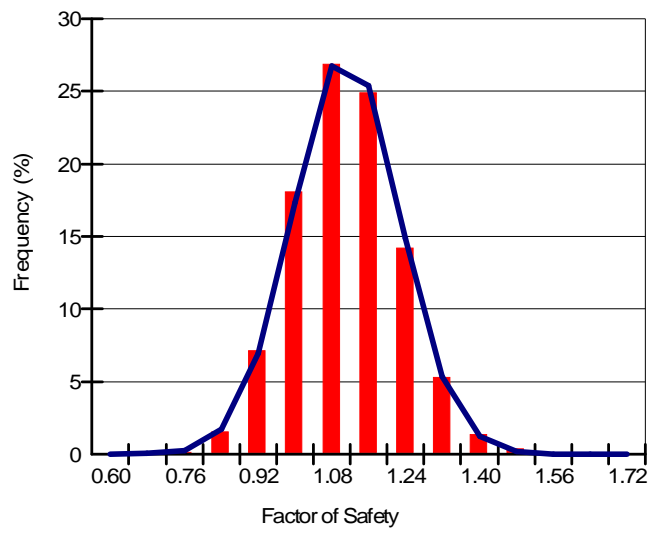

Fig. 8. The normal distribution curve (VS87)

\section{Probability Density Function}

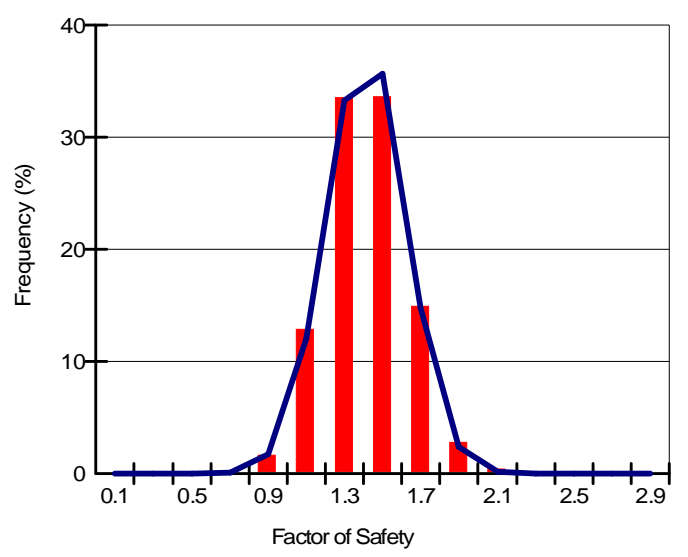

Fig. 10. The normal distribution curve (VS352)

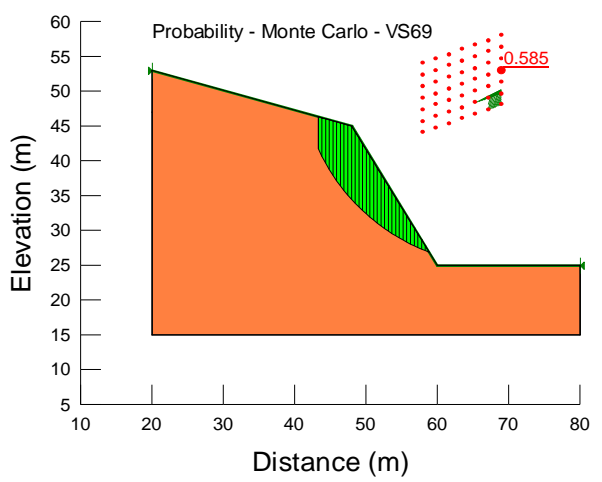

Fig. 12. Slip surface (VS69) 


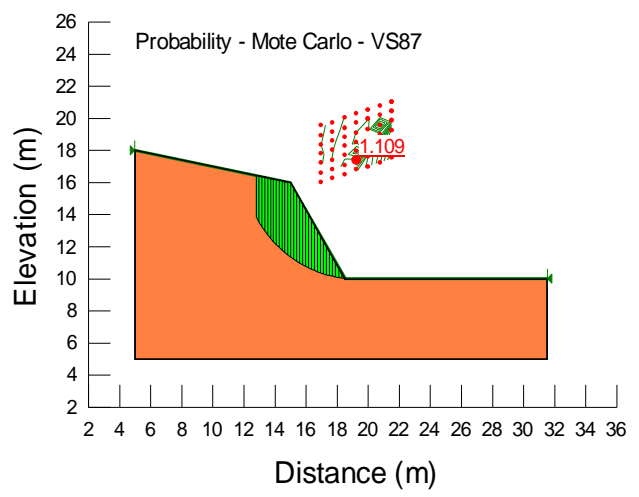

Fig. 13. Slip surface (VS87)

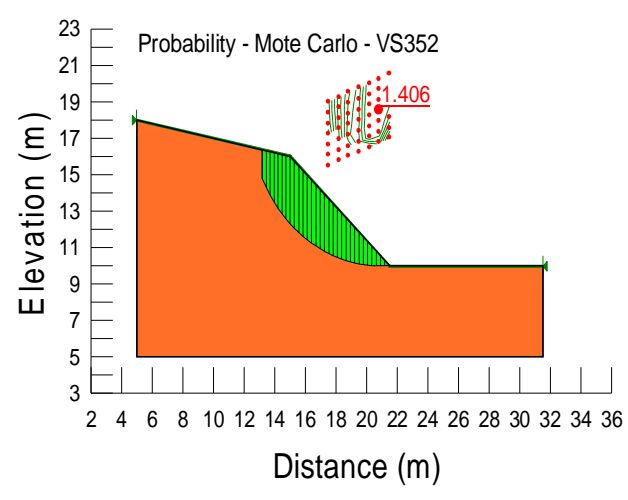

Fig. 14. Slip surface (VS352)
Case 2: $\sigma$ values are calculated by the formula (2), basis on the experience of the authors in Table 1: averaged $\operatorname{cov}$ of $\varphi$ and $c$ as 0.25 ; averaged $\operatorname{cov}$ of $\gamma$ as
0.05; $r$ as -0.5 (Lumb, 1970; Grivas, 1981 and Wolff, 1985), applying for the two slopes VS87 and VS352.

Table 5. The statistical parameters of soil base on the experience of the authors

\begin{tabular}{|c|c|c|c|c|c|c|c|}
\hline \multirow{2}{*}{ Soil type } & \multicolumn{2}{|c|}{$\gamma\left(\mathbf{k N} / \mathbf{m}^{3}\right)$} & \multicolumn{2}{|c|}{$\varphi$ (độ) } & \multicolumn{2}{|c|}{$c(\mathbf{k P a})$} & \multirow{2}{*}{$r$} \\
\hline & $\mu$ & $\sigma$ & $\mu$ & $\sigma$ & $\mu$ & $\sigma$ & \\
\hline $\begin{array}{l}\text { Sandy clay mixed with } \\
\text { gravel (epdQ) }\end{array}$ & 17.98 & 1.0 & 18.25 & 4.6 & 17.25 & 4.3 & -0.5 \\
\hline $\begin{array}{l}\text { Clayey sand mixed with } \\
\text { gravel (epdQ) }\end{array}$ & 17.29 & 1.0 & 17.38 & 4.3 & 15.25 & 3.8 & -0.5 \\
\hline
\end{tabular}

Case 3: Statistical parameters $\mu, \sigma$ are the same in case 2, but $r=0$, applying for the two slopes VS87 and VS352.

Table 6. Results of case 2, 3 (Fig. 15-20)

\begin{tabular}{|c|c|c|c|c|}
\hline \multirow{3}{*}{ Statistical parameters } & \multicolumn{4}{|c|}{ Slope } \\
\hline & \multicolumn{2}{|c|}{ Case 2} & \multicolumn{2}{|c|}{ Case 3} \\
\hline & VS87 & VS352 & VS87 & VS352 \\
\hline The mean factor of safety, $F S_{\text {mean }}$ & 1.12 & 1.42 & 1.12 & 1.42 \\
\hline Reliability index, $\beta$ & 0.57 & 1.58 & 0.57 & 1.57 \\
\hline Probability failure, $P(\%)$ & 29.00 & 5.47 & 29.00 & 5.47 \\
\hline Standard deviation, $\sigma$ & 0.21 & 0.27 & 0.21 & 0.27 \\
\hline The minimum factor of safety, $\mathrm{FS}_{\min }$ & 0.25 & 0.34 & 0.25 & 0.34 \\
\hline The maximum factor of safety, $F S_{\max }$ & 2.02 & 2.49 & 2.02 & 2.50 \\
\hline Number of Mote Carlo trials & 1500 & 1500 & 1500 & 1500 \\
\hline
\end{tabular}

\section{Trang 82}




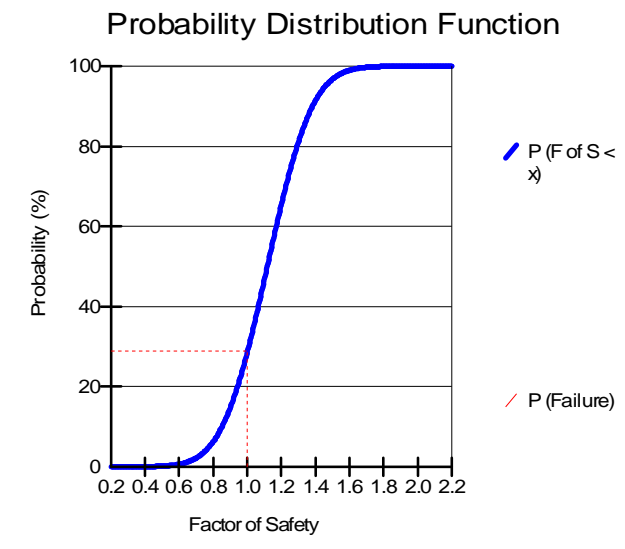

Fig. 15. The probability distribution curve (VS87)

Probability Distribution Function

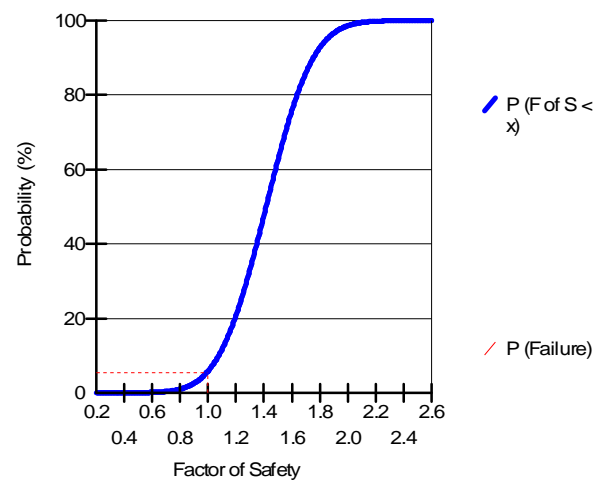

Fig. 17. The probability distribution curve (VS352)

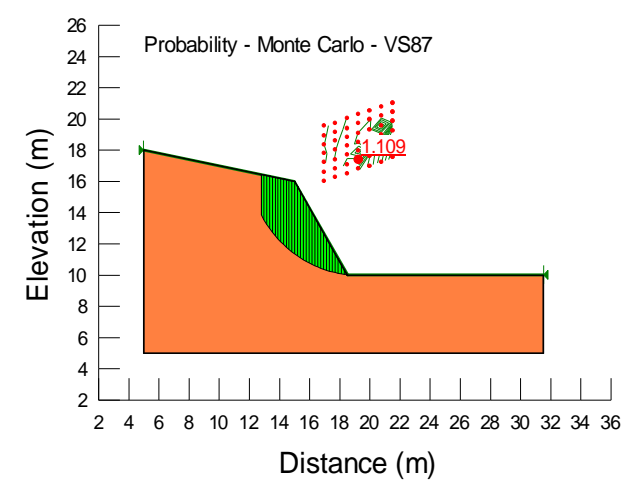

Fig. 19. Slip surface (VS87)

\section{CONCLUSIONS}

Comparison of the calculated results for the case 1, 2 and 3 can conclude that:

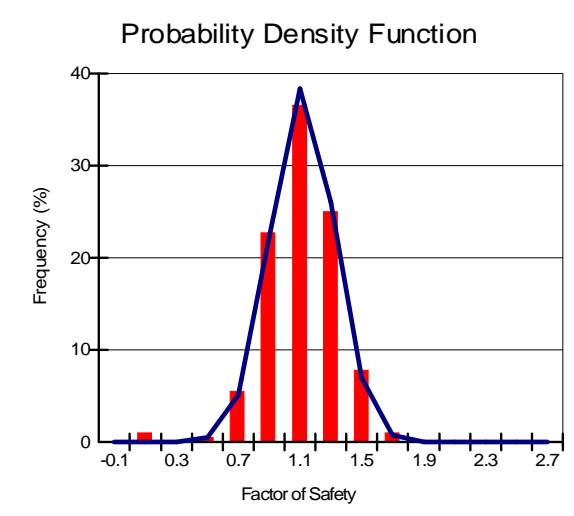

Fig. 16. The normal distribution curve (VS87)

\section{Probability Density Function}

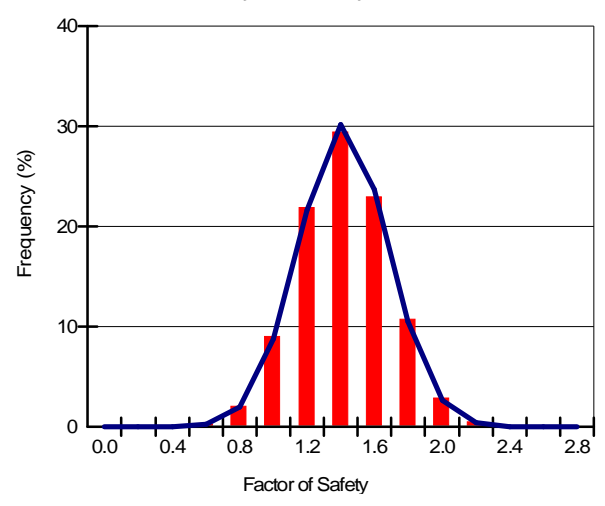

Fig. 18. The normal distribution curve (VS352)

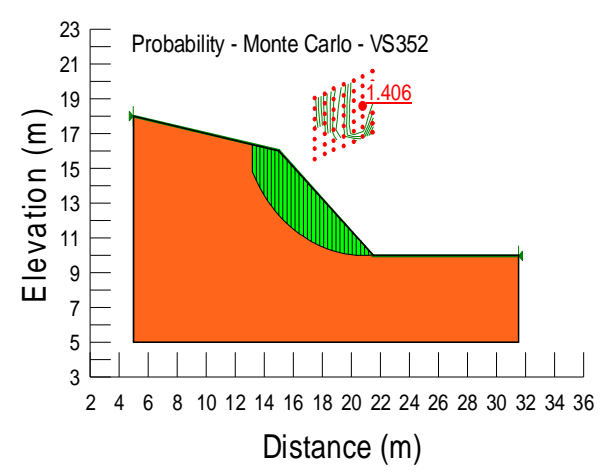

Fig. 20. Slip surface (VS352)

In the case 1, probability of failure of slopes VS26 and VS69 is $100 \%$ because the height and angle of the slope are exceeding. Slope VS352 has the lowest probability of failure because the height and angle of slope are small. 
Slopes composed by clayed sand, sandy clay mixed with gravel will have a low probability of failure and high reliability index as the slope angle less than 43 degrees.

The higher standard deviation of the input parameters is the greater the probability of failure is, although the safety factor does not change (VS87, VS352). Thus there is no direct relationship between safety factor and probability of failure. A slope with a high safety factor is not necessarily stable if the probability of failure is large.

Two parameters angle of internal friction $\varphi$ and cohesion $c$ have a very low correlation or no correlation with each other (case 2, 3). Due to the uncertainty of the input parameters $(\varphi, c$ and $\gamma$ will change a lot with moisture, especially during the rainy season), slope stability analysis must include the variation of them (i.e., the standard deviation).

The more parameters is entered the more trial runs of Mote Carlo will be used. However, many research shows that the number of trials is usually in the order of thousands times to ensure accuracy.

In the probabilistic analysis, to obtain the standard deviation with high accuracy only if set of samples is large enough. However, when the sample size is not large enough the formula (1), (2) can be used.

According to the limiting equilibrium methods, the same value of the safety factor often is applied for various slope although probability of stability is different, this issue is no suitable and wasteful. Therefore, the selection of design options, construction works to prevent optimally landslides should consider the factor of safety in relation to the probability failure and reliability index.

Probability theory and reliability analysis is an effective tool in assessing slope stability under the effect of many random factors.

ACKNOWLEDGEMENTS: Financial support provided by University of Technology (VNU-HCM) in project 911 is gratefully acknowledged. The authors are grateful to the anonymous referees for critically reviewing the manuscript, and improved the clarity of this paper as wel.

\section{Áp dụng phương pháp xác suất theo mô hình Monte Carlo đánh giá ổn định mái dốc trên tuyến đường Nha Trang - Đà Lạt (đoạn qua huyện Khánh Vĩnh, tỉnh Khánh Hòa)}

- Nguyễn Thanh Danh

- Đậu Văn Ngọ

- Tạ Quốc Dũng

Trường Đại học Bách khoa, ĐHQG-HCM

\section{TÓM TÁT:}

Bài báo này trình bày phương pháp phân tích xác suất ổn định mái dốc theo mô hình Monte Carlo, kết quả đạt được là xác suất phá hủy của mái dốc và chỉ số độ tin cậy của hệ số an toàn có xét đến sự biến đổi ngẫu nhiên của các tham số cơ lý đất đầu vào. Dựa vào các thông tin này, các

kỹ sư địa kỹ thuật có thể đưa ra phưng án thiết kế các công trình phòng tránh một cách tối ưu. Thêm vào đó, bài báo cũng tổng hợp và trình bày các phương pháp đơn giản để xác định độ lệch chuẩn, ứng dụng xác suất phá hủy và chỉ số độ tin cậy trong phân tích đánh giá độ ổn định một số mái

\section{Trang 84}


dốc trên tuyến đường Nha Trang - Đà Lạt (Đoạn

qua huyện Khánh Vĩnh, tỉnh Khánh Hòa).

Từ khóa: Mô hình Monte Carlo, ổn định mái dốc, hệ số an toàn, chỉ số độ tin cậy.

\section{TÀI LIỆU THAM KHẢO}

[1]. M. Abbaszadeh, K. Shahriar, M. Sharifzadeh, and M. Heydari, "Uncertainty and Reliability Analysis Applied to Slope Stability: A Case Study From Sungun Copper Mine," Geotech Geol Eng vol. 29, pp. 581-596, 2011.

[2]. J. M. Duncan, "Factors of safety and reliability in geotechnical engineering," Geotechnical and Geoenvironmental Engineering, vol. 126, 2000.

[3]. D. C. Tobutt, "Monte Carlo simulation methods for slope stability," Computers \& Geosciences vol. 8, pp. 199-208, 1982.

[4]. J. Krahn, Stability Modeling with Slope/W - An Engineering Methodology. 1400, 633 - 6th Ave SW, Calgary, Alberta, Canada T2P 2Y5: GEOSLOPE/W Intenational Ltd, 2004.
[5]. A. M. Hassan and T. F. Wolff, "Search algorithm for minimum reliability index of earth slopes," $J$. Geotech. Geoenviron. Eng, vol. 125, pp. 301308, 1999.

[6]. J. T. Christian, C. C. Ladd, and G. B. Baecher, "Reliability applied to slope stability analysis," Geotechnical Engineering, vol. 120, 1994.

[7]. The Department of Science and Technology of Khanh Hoa, "Studying geological conditions, hydrology in moutainous Khanh Son and Khanh Vinh districts. Proposing solutions to construct works of sustainable transportation and irrigation ", Khanh Hoa 2011 